\title{
Los estudios electorales en México (1988-1998): una mirada desde la transición democrática
}

Miguel Armando López Leyva

Flacso - Sede México

\begin{abstract}
A partir de las competidas elecciones de 1988, el interés de la academia mexicana se ha centrado en los procesos electorales como un termómetro efectivo de la transición política mexicana. Así lo muestra la variedad de textos que sobre el tema han sido publicados desde entonces. No obstante, ¿es posible asumir esa perspectiva? En el presente trabajo se argumenta, mediante la lectura crítica y clasificación de una selección de escritos electorales de la transición, que las elecciones en un proceso prolongado de cambio político como el mexicano pueden servir de medidor efectivo siempre y cuando se asuman sus particularidades, por lo cual debe tenerse cautela en el modo como se utilizan los conceptos y modelos de la literatura de las transiciones.
\end{abstract}

\section{Introducción}

En la última década, el fenómeno electoral ha despertado un enorme interés de los estudiosos mexicanos, sólo comparable al mostrado en la transitología. ${ }^{1}$ Desde ambos miradores se ha intentado entender la dinámica política del país, tan peculiar en sus instituciones y prácticas. El resultado de este acercamiento arroja una multiplicidad de perspectivas difíciles de medir con un mismo parámetro.

En el presente texto se pretenden analizar aquellos escritos que trabajan el aspecto electoral desde la mirada de la transición. Esta combinación de perspectivas tiene un sentido lógico: si es que una condición necesaria de cualquier régimen democrático es la celebración periódica de elecciones libres y competitivas, ${ }^{2}$ entonces no se puede omitir su existencia cuando se

1 Término utilizado para nombrar a la literatura teórica de la transición a la democracia

2 Entendiendo por "elecciones libres y competitivas" aquellas en donde existe libertad del elector para emitir su voto, así como la posibilidad de escoger entre dos o más candidatos o listas de candidatos. Hermet, Guy: "Las elecciones en los regímenes autoritarios: bosquejo de un marco de análisis”, en Hermet, Guy et al.: ¿Para qué sirven las elecciones?, México, 1982, págs. 23-25. Según Nohlen, "el cambio fundamental de un sistema político dictatorial comienza con la celebración de elecciones competitivas. En consecuencia, no se exigen simplemente elecciones, sino elecciones libres". Nohlen, Dieter: Sistemas electorales y partidos políticos, México, 1995, pág. 11. 
evalúa una circunstancia de cambio político. ${ }^{3}$ Sin elecciones no hay democracia posible. ${ }^{4}$ Además, el ejercicio efectivo del sufragio es un paso decisivo y visible de la transición hacia la democracia. Es un medidor efectivo del alcance del proceso de cambio institucional dado que posibilita la alternancia y la distribución del poder en los distintos niveles de gobierno.

En ese tenor, vale preguntarse: ¿pueden cumplir los comicios ese papel en el análisis de la realidad mexicana, es decir, de ser un medidor efectivo de la transición? En otras palabras, ¿se justifica el sitio otorgado a las elecciones cuando el caso analizado cuenta con particularidades que lo diferencian de otros autoritarismos?

En las líneas que siguen presentamos los resultados de nuestra investigación bibliográfica acerca de los escritos electorales de la transición en México, guiada por las preguntas formuladas atrás. El objetivo central de este ejercicio comparativo es ofrecer, mediante una lectura crítica, una clasificación mínima de las interpretaciones de la transición electoral mexicana que ubique los términos de la discusión reciente, refiriéndonos a dos ejes articuladores: el uso conceptual del marco teórico de las transiciones y la función que se le otorga a las elecciones en un proceso de este tipo. ${ }^{5}$

3 O’Donnell y Schmitter destacan la importancia de la convocatoria a elecciones durante el periodo de tránsito democrático. Según ellos, la convocatoria a elecciones produce un efecto doble: por un lado, si tal declaración es creíble, se comienzan a modificar las relaciones de fuerza dentro y fuera del régimen; por otro lado, los partidos asumen el papel principal antes y después de la elección fundacional, pues es la primera ocasión en que se disputan seriamente los cargos electivos a escala nacional. Por ello es relevante sentar las bases para el "consentimiento contingente", el cual implica que "los actores acepten competir de modo tal que quienes ganen las elecciones ejerzan su superioridad política temporaria de manera de no impedir que asuman el gobierno quienes puedan obtener mayor apoyo en el futuro; y quienes las pierdan en el presente, acepten respetar la autoridad contingente de los ganadores para tomar decisiones imperativas, a cambio de permitírseles ocupar el gobierno y tomar decisiones en el futuro". O’Donnell, Guillermo y Schmitter, Philippe C.: Transiciones desde un gobierno autoritario. Vol. 4. Conclusiones tentativas sobre las democracias inciertas, Buenos Aires, 1994, págs. 96-97. Linz, por su parte, le da peso sustancial a la realización de elecciones, al grado de enarbolarlas como la clave del término de la transición: "Nuestra opinión es que la experiencia del gobierno ad interim temporal, sin una legitimación democrática, se puede considerar concluida cuando se haya formado un gobierno de elecciones libres, que demande la confianza sola y únicamente de un cuerpo de representantes. Lo anterior implica que por un periodo mayor de un año no existan reglas inobjetables sobre quien y con qué poderes debe gobernar". Linz, Juan: El factor tiempo en un cambio de régimen, México, 1994, pág. 52.

4 Esto se aprecia con claridad en las condiciones de la poliarquía que establece Robert Dahl: a) cada miembro de la organización lleva a cabo los actos que constituyen una expresión de preferencia entre alternativas programadas (el voto); b) el valor asignado a cada voto es idéntico; c) la elección vencedora es la alternativa que obtiene el mayor número de votos; d) cualquier miembro puede incluir su(s) alternativa(s) preferida(s) entre el conjunto de alternativas ya programadas; e) todos los individuos poseen información idéntica sobre las alternativas; f) las alternativas con el mayor número de votos desplazan a las alternativas con menor número de votos; $\mathrm{y}$ g) se ejecutan las órdenes de los funcionarios elegidos. Dahl, Robert: Un prefacio a la teoría democrática, México, 1987, págs. 110-111.

5 Los elementos considerados para realizar esta clasificación pueden leerse en el apéndice. 


\section{La apropiación del campo teórico}

Una primera aproximación tiene que tomar en cuenta que las interpretaciones mexicanas de la transición son de distinta naturaleza. Este punto es importante tenerlo presente en virtud de que influye en la modalidad de apropiación del campo teórico de las transiciones. La división de enfoques resultante parte de la perspectiva de acercamiento al tema (Cuadro 2), a saber:

1. Periodo histórico. Es el más abundante en interpretaciones. En él se concentran aquellas que tratan la dinámica de la transición electoral desde una perspectiva histórica, esto es, poniendo énfasis en tramos de tiempo medianamente largos, comparables en aspectos concretos.

2. Coyuntura electoral. Aquí se concentran los escritos que abordan unas elecciones determinadas, desglosando la relación entre resultados electorales, partidos políticos y/o marco legal.

3. Partido. En esta sección se analiza el desempeño de un partido político en particular en el contexto de la transición democrática.

4. Corporativo. Consideramos pertinente ubicar una casilla con este título porque su alcance es distinto. Es decir, el tratamiento que este enfoque da a la cuestión electoral se parece mucho al del enfoque del periodo histórico, pero existe una diferencia clave: incorpora el tema del corporativismo - representación de intereses- como un elemento decisivo en la dirección del voto.

5. Democrático. Este enfoque se distingue de los demás no por los temas tratados - cualquiera de los enfoques hace referencias explícitas a la democracia - sino por el tono del contenido, de carácter reflexivo. Es decir, aquí el impulso reside en debatir el desarrollo de la idea de la democracia, tanto en el ámbito teórico como en el empírico.

Una vez identificados los enfoques pasemos a la confrontación de escritos con un modelo del campo teórico de las transiciones (Cuadro 1). ${ }^{6}$ La pregunta a responder es: ¿cómo se apropian del campo teórico de las transiciones? Enunciada de otra manera, ¿de qué modo sirve el modelo teórico para pensar el presente mexicano?

6 Este ejercicio se basa en tres claves de lectura: a) los autores "clásicos" o las referencias bibliográficas, b) los conceptos rescatados en la argumentación (el régimen autoritario, la transición y la instauración del régimen democrático, y el significado explícito de "democracia") y c) la función de los conceptos en el entendimiento y explicación del fenómeno político —en nuestras palabras, el tipo de apropiación al que se ajustan las interpretaciones. El asunto de la funcionalidad de los conceptos es el más importante de todas las claves. 
Definimos cuatro tipos de apropiación y los resumimos del modo siguiente (Cuadro 3):

1. Apropiación del modelo. Es, desde nuestro punto de vista, el mecanismo más eficaz para enfrentarse al fenómeno electoral, no porque la realidad tenga tercamente que calzar en el modelo, sino por el motivo contrario. La apropiación apegada al modelo de transición permite, principalmente, visualizar las limitaciones de éste y la necesidad de ajustarlo o repensarlo, lo cual es particularmente cierto en el caso mexicano, plagado de ambigüiedades y claroscuros. Quizás por esta causa se encuentren solo tres trabajos de esta naturaleza, como puede verse en el cuadro.

2. Apropiación de conceptos. En este tipo de apropiación el modelo no se usa estrictamente, pero se retoman conceptos e ideas de los transitólogos clásicos para sustentar los argumentos de cada autor, sea como pie de página, o bien, mediante un espacio para hacer un recuento del tema. Conviene destacar que la apropiación de conceptos no demerita la calidad de los textos así clasificados, solo valora el método utilizado para incorporar el marco conceptual de las transiciones.

3. Apropiación del esquema. Se caracteriza principalmente por presentar una "figura sin contenido". Es decir, en los escritos clasificados por esquema prácticamente no se cita a los transitólogos clásicos, pero se usan los conceptos afines a esa literatura sin profundizar en ellos. La "figura" transición carece de "contenido" modélico o conceptual.

4. No-apropiación. En este espacio se concentran la mayoría de los escritos seleccionados. Se caracteriza básicamente por no usar referencias a la literatura de las transiciones, ${ }^{7}$ y por utilizar el término "transición" como un contexto general que no produce mayores explicaciones sobre la transición misma. En la "no-apropiación" existe un vínculo expreso entre lo electoral y la transición, pero ésta última solo es referencia obligada, una especie de "foco de atención" para el lector.

7 Con la excepción de Crespo, José Antonio: "La evolución del sistema de partidos en México", Foro Internacional, 124, vol. XXXI, núm. 4, abril-junio, México, 1991, págs. 599-622; Hernández Rodríguez, Rogelio: "La difícil transición política en México", Mexican Studies/Estudios Mexicanos, vol. 8, núm. 2, summer 1992, México, págs. 237-257; Loaeza, Soledad: "Derecha y democracia en el cambio político mexicano: 1982-1988”, Foro Internacional, 120, vol. XXX, núm. 4, abriljunio, México, 1990, págs. 631-658; y Mora Heredia, Juan: "Electores y democracia en el México de la transición”, El Cotidiano, núm. 65, noviembre, México, 1994, págs. 82-83 y 94-97. 
Vista con más detalle, la clasificación por apropiación es ilustrativa de varias cosas:

1. Todos los trabajos contenidos en las apropiaciones del modelo y de los conceptos ${ }^{8}$ corresponden al enfoque de periodo histórico, lo cual parece indicarnos que el abordaje de mediano plazo es propicio para el estudio de la transición que, como proceso político, no puede limitarse estrictamente a una coyuntura electoral o a un actor concreto.

2. Los 32 textos seleccionados hablan de la transición de diversos modos, sea como "transición política", "transición democrática", "transición a la democracia" o "transición hacia la democracia". Este hecho no es banal, si se toma en cuenta que en al menos las tres últimas expresiones se acepta de antemano cierta dirección (o contenido) del rumbo: el tránsito es democrático o se dirige a (hacia) la democracia. ${ }^{9}$ Además, obsérvese que la expresión "transición" se suele confundir con (o hacer sinónimo de) otras igualmente importantes pero diferentes, tales como "transformación democrática", "cambio político" y "democratización".

3. Las referencias presentes en algunas de las interpretaciones no son las mismas. Como era de esperarse de las apropiaciones del modelo y de conceptos, ahí se concentra el mayor número de referencias bibliográficas, siendo O'Donnell y Schmitter la principal (de 12 textos, 10 las incluyen). En tres de los escritos clasificados aparece Rustow, en cuatro Morlino y en seis Przeworski. Esto nos indica el predominio de la transitología de la primera etapa, según la división de Ruth Berins Collier. ${ }^{10}$

8 Con excepción de Aziz Nassif, Alberto: "El 6 de julio y el país de la transición”, Incertidumbre y democracia en México, Cuadernos de la Casa Chata, núm. 177, Centro de Investigaciones y Estudios Superiores en Antropología Social, México, 1990, págs. 37-72; y Buendía Laredo, Jorge: "Incertidumbre y comportamiento electoral en la transición democrática: la elección mexicana de 1988", Política y Gobierno, vol. IV, núm. 2, segundo semestre, México, 1997, págs. 347-375.

9 Al respecto, Becerra hace una distinción poco convincente entre "transición democrática" y "transición a la democracia": la primera expresión está ligada a la perspectiva gubernamental, de perfeccionamiento de la institucionalidad vigente; la segunda se liga a posturas no gubernamentales, que con distintas estrategias buscan una "verdadera democratización del sistema político". Becerra, Pablo Javier: "Las elecciones de 1991: la transición difícil”, Polis (Anuario de Sociología), 91, Universidad Autónoma Metropolitana - Iztapalapa, México, 1991, págs. 197-198.

10 Collier, Ruth Berins: "Democratic transition", en Barry Clarke, Paul y Foweraker, Joe (eds.): Encyclopedia of Democratic Thought, London, Routledge, 2001, págs. 213-217. Según Collier, una de las fases de evolución de la literatura de las transiciones estuvo marcada por los sucesos de la Europa meridional y de Sudamérica, la cual comparte algunas características propias: un estilo analítico no determinista y probabilístico, descriptivo más que causal, basado en el actor (sus metas y la disposición para alcanzarlas) e insistente en el papel relativo de la autonomía de la élite, las habilidades de liderazgo y la contingencia. En esta fase, el trabajo pionero de O'Donnell y Schmitter, junto con otros que no viene al caso mencionar aquí, representa adecuadamente esta fase originaria. 
4. En cuanto al significado asignado al término "democracia", siempre está presente ${ }^{11}$ la dinámica electoral en primer plano: las elecciones, la alternancia en el poder, el pluripartidismo y/o el establecimiento de reglas equitativas para la competencia. El contenido procedimental de la democracia expresa la manía por lo electoral que recorre al mundo académico mexicano.

\section{El espacio privilegiado de las elecciones}

La segunda parte de la contrastación de los estudios de la transición electoral ${ }^{12}$ pretende contestar lo siguiente: ies la democracia electoral la que mejor define un proceso de transición democrática? En la práctica, ¿qué lugar ocupan las elecciones en los estudios electorales de la transición mexicana? Porque puede pensarse que forjan momentos de ruptura, de aceleración de la transición, de reforma o bien, de conservación institucional. Cualquiera de estas opciones nos retrotrae al asunto de las fronteras difusas entre el autoritarismo y la democracia que, como se ve, todavía está latente.

La división de interpretaciones en este apartado se hizo siguiendo un criterio simple: el año de inicio de la transición. Ésta división tiene un inconveniente, refleja la pluralidad de fechas manejadas como el comienzo del proceso, pero tiene una ventaja inmejorable, pues con la fijación del año en cuestión es dable ubicar con precisión el factor decisivo que desencadena el cambio.

En esta clasificación (Cuadro 4) detectamos, al menos, dos trampas académicas. La primera se debe a una ambigüedad para señalar los años determinantes de la transición. Textualmente, cada uno de los siguientes autores no establece con exactitud el comienzo de la transición. Hernández Rodríguez dice: "Desde hace algunos años, pero en especial desde las elec-

11 Con excepción de Fernández Christlieb, Paulina: "Partidos políticos y sociedad civil ante la inexistente transición a la democracia en el México de hoy", Rodríguez Araujo, Octavio (coord.): Transición a la democracia. Diferentes perspectivas, México, 1996, págs. 193-212; Hernández Rodríguez, Rogelio: "La difícil transición..."; y Semo, Ilán: "Democracia de élites versus democracia societal: los paradigmas de la pretransición mexicana", en Semo, Ilán et al: La transición interrumpida. México 1968-1988, 2. a edición, México, 1994, págs. 191-228.

12 Este segundo ejercicio consta de dos claves de lectura: a) la función asignada a las elecciones en el contexto del cambio y b) la fase en que se instalan o que se deriva de su celebración bajo condiciones competitivas. Justamente de aquí viene el carácter procedimental de la democracia, al entendérsele como un conjunto de reglas reguladoras de la competencia y del acceso al poder público. 
ciones presidenciales de 1988 , se ha insistido en que el sistema político mexicano se encamina hacia su transformación democrática". ${ }^{13}$ Loaeza argumenta: "No obstante los múltiples tropiezos de los comicios de julio de 1988, en los meses siguientes la idea de que el país estaba comprometido en una transición a la democracia se apoderó de la imaginación pública mexicana". ${ }^{14}$ Reyes del Campillo, por último, afirma: "Sin duda ha sido un largo y difícil camino, pero el mejoramiento de las reglas y las prácticas democráticas son una constante desde la conflictiva elección de 1988". ${ }^{15}$

La trampa radica en el decir pero no decir. Ese es el sentido de las frases "se ha insistido", "ha sido", o de achacar el surgimiento de la transición a una inasible "imaginación pública mexicana". Estas ambigüedades dicen poco de las posturas de los autores, quizás abonando el camino para un futuro cambio de opinión. ${ }^{16}$

La segunda trampa es de orden conceptual, tiene que ver con un error de apropiación conceptual. De la revisión detallada de la fase en que se sitúa la realidad mexicana, salta a la vista un error en cuatro textos. El error estriba en separar tajantemente la transición en sí misma del proceso de liberalización. La liberalización tiende a ser una especie de antecedente de la transición, pero no forma parte de su estructura, de sus etapas o fases.

Este fallo afecta directamente la cuestión temporal del inicio, porque si la liberalización es un proceso separado, entonces la fecha de ese proceso y la de la transición en sí son distintas y no coinciden. Loaeza dice que la transición comienza en 1982, pero la antecede un proceso de liberalización gradual — exitoso en cuanto recompuso al régimen — que data de doce años atrás. ${ }^{17}$ Sánchez Susarrey arguye que la transición comienza en 1988, precedida por una liberalización proveniente de 1977, año de la primera reforma política significativa. ${ }^{18}$ Finalmente, Santiago propone que el pro-

13 Hernández Rodríguez, Rogelio: "La difícil transición ...”, pág. 237.

14 Loaeza, Soledad: "La lenta construcción del pluralismo mexicano", en Couffignal, Georges (comp.): Democracias posibles. El desafío latinoamericano, Buenos Aires, 1994, pág. 175.

15 Reyes del Campillo L., Juan: "La transición se consolida", El Cotidiano, núm. 85, septiembre-octubre, México, 1997, pág. 4.

16 La misma Loaeza, asegura en un texto anterior que la crisis política de 1982 se convirtió en una transición: "en una etapa en la que la democracia luchaba por instalarse y el autoritarismo se tambaleaba parcialmente". Loaeza, Soledad: "Derecha y democracia...”, págs. 631-632.

17 Loaeza, Soledad: "Derecha y democracia...", pág. 637

18 Sánchez Susarrey, Jaime: "México: la transición democrática aquí y ahora", en Barros Horcasitas, José Luis et al. (comps.): Transición a la democracia y reforma del estado en México, México, 1991, pág. 156; y Sánchez Susarrey, Jaime: "Estado y perspectivas de la transición en México", en Cambio XXI, Fundación Mexicana (coord.): Las transiciones a la democracia, México, 1993, pág. 315 
ceso de liberalización inicia en 1977 y no ha terminado, lo cual indica que no ha iniciado la transición. ${ }^{19}$

El traslape entre el concepto general y uno de sus componentes conduce a la trampa: se considera que la liberalización, siendo un proceso que puede o no conducir a la democracia, no es parte del tránsito democrático, sino una base aprovechable si el impulso de los actores y las condiciones así lo permiten. La indefinición en la dirección de la liberalización parece nulificarla para formar parte de la transición, apreciación ausente - vale decirlo- en los modelos teóricos de las transiciones a la democracia.

Además, la transición a la democracia aparece como sinónimo de instauración democrática y, más que eso, de la democracia misma. Por tanto, la transición aparece como un elemento desligado de la apertura política. La lógica de esta trampa se lee así: puede aceptarse la existencia de la liberalización del autoritarismo mexicano sin que marque el transcurso de la transición. Esta última aparece cuando existe voluntad negociadora e intenciones democráticas, y los actores políticos reforman las reglas del juego con rumbo franco a la democracia. De modo que la liberalización es un proceso dúctil que se alarga por los fueros del régimen autoritario $-\mathrm{y}$ de los que comparten esta visión errática - como si ella misma no representara un cambio al interior del mismo régimen.

En suma, transición y liberalización aparecen como conceptos excluyentes uno del otro: si existe el primero, el segundo funge como antecedente prescindible; si existe el segundo, el primero no necesariamente tiende a cobrar vida. Recuérdese que de acuerdo con la literatura de las transiciones, liberalización y democratización - término éste último que los autores mexicanos citados sustituyen por el de transición- son dos fases que no necesariamente tienen una secuencia definida, ya que pueden, o no, ocurrir simultáneamente y en un lapso muy breve de tiempo.

¿Qué es lo que se desprende de la clasificación del Cuadro 4? Por un lado, el dominio de dos años, 1977 y 1988, ambos con un significado electoral indiscutible. 1977 se relaciona con la reforma política, con la ley electoral promulgada en 1978 o con un proceso creciente de reformas a la legislación electoral. ${ }^{20} 1988$, por otro lado, se recuerda por los comicios

19 Santiago Castillo, Javier: "Proceso de liberalización política y legislación electoral", Polis (Anuario de Sociología), 95, Universidad Autónoma Metropolitana - Iztapalapa, México, 1996, págs. 113-114.

20 Téngase en cuenta que el precedente de la reforma política de 1977 fueron los comicios de 1976, en los que el candidato del PRI contendió sin contendiente, curiosa paradoja en un régimen preocupado por incentivar — aunque sea artificialmente— opciones partidarias de distinta carga ideológica. 
presidenciales conflictivos, el colapso electoral que se produjo o la posibilidad de la alternancia. De hecho, de las fechas clasificadas, solo dos hacen alusión a aspectos de orden económico: los ochenta y 1982.

En lo que respecta a la "fase", obtenemos que 12 interpretaciones hablan de algún tipo de crisis política, de límites sistémicos o de instituciones debilitadas; la mitad de ellas habla — se consideren juntas o separadas la transición y la liberalización- de que el país está envuelto en una transición, así se le califique de "distinta", "incompleta", "larga y difícil", "limitada", "gradual", "peculiar" o "incierta". Esta concentración de argumentos en las fases de crisis y transición, pero sobre todo las adjetivaciones que ésta amerita en la mayoría de las interpretaciones clasificadas, nos hablan por sí mismas del carácter anómalo de nuestra transición política: un proceso prolongado y distinto que merece atención especial de la investigación comparada..$^{21}$ Aunque también están las visiones - las menos, por cierto- pesimistas: Semo habla de una etapa de pretransición (inexistente en los modelos teóricos); ${ }^{22}$ Loaeza, de un régimen plural lejano de su transformación; ${ }^{23}$ y Hoyo Arana, de democracia formal con características autoritarias..$^{24}$

\section{Un diagnóstico a partir del marco teórico y de las elecciones}

Con la descripción de los dos ejes articuladores de las interpretaciones mexicanas de la transición electoral, concluyamos con las siguientes observaciones.

21 La noción de transición prolongada o retardada ha dominado en las últimas fechas la perspectiva sobre nuestro proceso político. Al respecto, consúltese Eisenstadt, Todd A.: “¿Remolinos en la tercera ola? Las transiciones prolongadas en las teorías sobre democratización”, en Ortega Ruiz Reynaldo Yunuen (ed.): Caminos a la democracia, México, 2001, págs. 87-120; Loaeza, Soledad: Incertidumbre y riesgo en transiciones prolongadas. La experiencia mexicana y el Partido Acción Nacional, Documentos de Trabajo, núm. 14, Facultad Latinoamericana de Ciencias Sociales, México, 2000; Ortega Ruiz, Reynaldo Yunuen: "Tipos de transición: un estudio comparativo de España y México", Ortega Ruiz, Reynaldo Yunuen (ed.): Caminos a la..., págs. 267-321; Schatz, Sara: Elite, Masses, and the Struggle for Democracy in Mexico. A culturalist approach, Westport, 2000; y Schedler, Andreas: "The two - level game of democratization by elections", paper prepared for presentation at the Congress of the Canadian Association for Latin American and Caribbean Studies (CALACS), Antigua, Guatemala, 22-24 february 2001.

22 Semo, Ilán: "Democracia de élites...".

23 Loaeza, Soledad: "La lenta construcción...".

24 Hoyo Arana, José Luis: "Las elecciones de 1991 y las posibilidades de la transición a la democracia", Estudios Políticos, tercera época, núm. 10, abril-junio, México, 1992, págs. 73-85. 
1. Existen tres posibilidades para apropiarse del campo teórico de las transiciones. La funcionalidad de los conceptos es el aspecto clave en la apropiación teórica. No basta con utilizarlos porque están a la mano o porque son un pretexto cómodo para hablar de cualquier cosa, sino vislumbrar su potencial explicativo.

En ese tenor, puede entenderse el predominio de los trabajos clasificados como no apropiaciones. Ellos reflejan la penetración que ha tenido en el mundo académico la transitología pero, a la par y por la baja funcionalidad de los conceptos, cuán alejadas están de ofrecer una explicación rigurosa cuando se asume como moda un término de alcance medio.

Situación que se agrava al percatarnos que, de los 17 trabajos denominados no apropiaciones, solamente dos no tienen respaldo institucional, de acuerdo a uno de los criterios establecidos en la selección de textos. ${ }^{25}$ Un dato que lleva a la conclusión de que el "rigor y seriedad analíticos" no riñe con la falta de respaldo académico.

A pesar de lo anterior, la apropiación del modelo nos parece la más conveniente porque, según hemos dicho ya, permite apreciar los alcances y límites del marco conceptual. Por este camino son pocos quienes se animan a andar, aunque los resultados de sus análisis sean sugerentes y rigurosos, lo cual abre expectativas para jugar —en el más serio sentido del verbocon los varios modelos de transición existentes.

Esos pocos son Cansino, Crespo y Merino. Cansino hace uso de una extensa gama de autores de la investigación de la transición, pero asume explícitamente las concepciones de Linz y Morlino. Su premisa mayor es que México vive "un proceso de liberalización política de larga duración 1977 a la fecha - en el que pueden observarse avances y retrocesos en términos de garantías políticas y civiles concedidas". ${ }^{26}$

Crespo recurre a Huntington y a O'Donnell y Schmitter para plantear un esquema de "correlación de fuerzas entre promotores y opositores al cambio democrático". Para él, en 1988 el equilibrio de poder entre fuerzas enfrentadas no tuvo un desenlace claro hacia la transición, lo que explica el porqué nuestra transición haya sido "peculiar, lenta, tortuosa, sorpresiva e incierta" ${ }^{27}$ Merino hace un símil entre el modelo de fases de Rustow y la

25 Véase el apéndice.

26 Cansino, César: "La transición política", en Construir la democracia. Límites y perspectivas de la transición en México, México, 1995, págs. 13-49.

27 Crespo, José Antonio: Institucionalización autoritaria y consolidación democrática: el caso de México, Documentos de Trabajo, núm. 47, Centro de Investigación y Docencia Económicas, México, 1997. 
situación mexicana prevaleciente a inicios de los noventa. Sugiere que nos encontramos en la "fase preparatoria", caracterizada por una prolongada lucha política y el conflicto, y esboza - retomando a Morlino y al mismo Rustow- cinco escenarios posibles para el futuro mediato. ${ }^{28}$

El hilo que une a estas tres interpretaciones del modelo es la idea de que la transición mexicana es un proceso de largo alcance, el cual no ha terminado y que tuvo un momento de ruptura importante en los comicios federales de 1988, aunque solo Merino vea en ese año el inicio de la transición. El asunto de la temporalidad nos interesa porque indica el amplio periodo por el que se ha desplazado el cambio político mexicano lo que, de suyo, impide el uso de la transitología sin restricciones.

2. La democracia electoral es la que mejor define un proceso de transición democrática, pero difícilmente lo hace con nitidez en un caso como el mexicano. Si nos remitimos al Cuadro 3, vemos que en solo cuatro trabajos $^{29}$ la democracia implica algo más que elecciones, pluripartidismo y alternancia. Sin embargo, la variedad de fechas señaladas como el comienzo de la transición (Cuadro 4) nos indica que, aunque los comicios ocupen un espacio privilegiado en la explicación de nuestro proceso de cambio, no son suficientes para entender la transición mexicana. Esto es, no se observa un momento de ruptura electoral específico que distinga el autoritarismo de la democracia, sino una secuencia gradual de cambios o rupturas que aceleran o detienen la instauración democrática.

Ese es el sentido de la aportación de Víctor Manuel Reynoso, para quien "el escenario de las elecciones y los partidos en México parece ser el de un cambio sin rupturas, o más bien: con proceso de pequeñas rupturas, y no con una ruptura que acabe con el sistema anterior (de partido hegemónico) y dé lugar a un sistema democrático", siendo esas rupturas parte de "una madurez gradual de las instituciones democráticas". ${ }^{30}$ En ese tenor, podemos afirmar que el proceso político mexicano ha corrido por el sendero de las reformas.

28 Merino, Mauricio: "Democracia, después", en La democracia pendiente: ensayos sobre la deuda política de México, México, 1993, págs. 65-95.

29 Los de Fernández Christlieb, Paulina: "Partidos políticos y...”; Loaeza, Soledad: "Derecha y democracia..."; Meyer, Lorenzo, y Reyna, José Luis: "México. el sistema y sus partidos: entre el autoritarismo y la democracia", en Meyer, Lorenzo, y Reyna, José Luis (coord.): Los sistemas políticos en América Latina, México, 1989, págs. 305-328; y Salazar, Luis: "Partidos políticos y transición a la democracia en México", Sociológica, año 4, núm. 11, septiembre-diciembre, México, 1989, págs. 27-42.

30 Reynoso, Víctor Manuel: "Las razones y las formas de una transición gradual. México 1988-1994”, en Dutrénit Bielous, Silvia (coord.): Huellas de las transiciones políticas. Partidos y elecciones en América Latina, México, 1998, págs. 163 y 205. 
En suma, las elecciones mexicanas podrían ser tomadas como medidor de la transición mexicana, siempre y cuando se asuma que: a) la democracia electoral es el horizonte más cercano en el camino del cambio, pero no el indicador de mayor peso en tanto que: b) no existe un punto de ruptura electoral determinante en el lapso de nuestro interés, lo cual ha hecho gradual la renovación del régimen político mexicano.

\section{Una reflexión final sobre la transición mexicana}

El debate acerca de la transición mexicana sigue abierto. La cuestión electoral no pierde vigencia, transcurrida ya la más competida elección presidencial de nuestra historia, la del 2 julio de 2000. La novedad radica en que la posibilidad de alternancia en el poder se hizo realidad con el triunfo del candidato del Partido Acción Nacional (PAN). Este asunto deja de lado los problemas anteriores, relacionados con la parcialidad o injusticia tanto de las reglas de competencia como de los encargados de aplicarlas, lo cual llevaba siempre a un mismo resultado: un partido hegemónico prácticamente invencible mediante la realización de elecciones "fraudulentas".

Este cambio trascendental en la vida pública mexicana repercute directamente en la manera que tenemos de entender la realidad. Nuestros parámetros son ahora otros, lo cual nos debe llevar a comprender la naturaleza democrática de nuestra actual situación. Porque México puede ser citado ya como una democracia electoral, un régimen político que permite la celebración periódica de elecciones libres, competitivas y limpias, bajo un marco de competencia aceptada por todos los protagonistas de la política, donde se respetan los derechos civiles y políticos básicos.

El reconocimiento democrático actual, sin embargo, no se ha asentado del todo, principalmente en las apreciaciones provenientes del ámbito académico. ${ }^{31}$ Este defecto en el análisis se corresponde ampliamente con la extensa discusión del proceso de transición que nos ocupa, tal como se percibe en los escritos aquí tratados sobre la transición electoral.

31 En contraste, la sociedad mexicana parece percibir favorablemente la existencia de democracia. Según una encuesta del periódico Reforma, en diciembre de 2000, a la pregunta “¿considera que hoy en día México es una democracia?", el 59\% de los encuestados respondieron "sí es una democracia", que puede compararse con el $45 \%$ que respondió en el mismo sentido en enero del mismo año. Moreno, Alejandro: "La sociedad mexicana y el cambio", Este País, núm. 133, abril, México, 2002, pág. 79. 
Por lo anterior, conviene establecer tres conclusiones breves relativas al ejercicio comparativo desarrollado en el presente texto. Se trata de precisar las limitaciones del enfoque transitológico a la hora de aplicarlo al caso mexicano.

El regateo democrático o de las virtudes de la alternancia. Los escritores mexicanos analizados en estas cuartillas regatean el calificativo "democrático" al régimen mexicano, así sea en su versión procedimental. Pueden haber sido claros los avances en materia de libertad del sufragio y competitividad partidista y el regateo insiste en nuestra calidad autoritaria: el voto no es libre porque persisten los intentos - exitosos en ocasiones- por coaccionar y dirigir el sentido que asume, y la competitividad está por verse mientras el PRI haga uso de todos los recursos a su disposición para ganar.

La insistencia en subrayar los defectos de la práctica democrática se evidencia con mayor fuerza en el discurso político opositor, y se le agrega al regateo democrático la palabra mágica que se convirtió en el "caballito de batalla" del proceso electoral pasado: la alternancia. La democracia, nos dicen las oposiciones, no es cuestión de gradaciones: se es o no se es democrático. No importa tanto la distribución plural del poder previo a la alternancia, mientras el eje articulador — la presidencia - siguiera en manos del PRI.

Vistas de este modo las cosas, el punto culminante o la ruptura esperada de la transición, el momento clave del transito mexicano, se definió con la alternancia. Mientras no llegara, cada elección era la extensión de un proceso de suyo largo, dador de vida para el "régimen caduco". El tributo permanente a lo electoral se alimentaba, felizmente, a sí mismo: el regateo democrático perviviría por la falta de alternancia y la falta de alternancia podía explicar por qué México no entraba de lleno en el rango de las democracias.

El muro autoritario o de la necesidad de repensar el pasado. El análisis del autoritarismo se transformó en un muro impenetrable, pues el pasado mexicano se estudiaba con la ayuda de las herramientas teóricas disponibles para cualquier caso similar, la más común, la concepción de Juan J. Linz. ${ }^{32}$ Así, la preocupación académica se topaba con la valla infran-

32 Linz, Juan: "Una teoría del régimen autoritario: el caso de España", en Allardt, Erik, y Rokkan, Stein (eds.): Mass politics: studies in political sociology, New York, 1970, págs. 203-263; y Linz, Juan: "Totalitarian and authoritarian regimes", en Greenstein, F. I. y Nelson W. Polsby (eds.): Handbook of Political Science. Vol. III. Macropolitical Theory, Reading, Massachusets, Addeson Wesley, 1975, págs. 175-373. 
queable de nuestro autoritarismo, sin considerar seriamente sus peculiaridades, a saber:

a) El carácter anómalo del autoritarismo. Un error básico cruza muchas de las interpretaciones reseñadas: no es el mismo punto de partida al de otras experiencias internacionales. La anomalía autoritaria mexicana tiene dos rasgos esenciales, diferenciadores de cualquier otra transición: el papel discreto de los militares, quienes una vez retirados a sus cuarteles desde que se civilizó el poder, solo aparecieron en coyunturas difíciles; y la recurrencia a elecciones, las cuales nunca dejaron de celebrarse aunque no tuvieran efectos prácticos en la selección de gobernantes. Esto es esencial, ya que los comicios, poco a poco, pero sobre todo en los años ochenta, dejaron de ser un mecanismo de recambio dentro de una misma elite gobernante y se transformaron en medio de expresión de protesta y de decisión pública. La persistencia de las elecciones nos permite entender la relativa calma en que transcurrió nuestra transición,,$^{33}$ pues eran un dispositivo formalmente existente que tenía que ser activado a través de la presión social.

b) El carácter informal del autoritarismo. La transición se refiere, explícitamente, al periodo de tiempo que media entre un régimen que muere y uno que se instaura. El cambio en el país ha recaído parcialmente en sus instituciones, pero principalmente en su funcionamiento. El régimen mexicano, siendo formalmente democrático, se ha modificado exclusivamente en sus instituciones electorales, y ha sido suficiente para accionar el cambio: lo electoral evolucionó en sentido democrático, pues la institución encargada de organizar las elecciones -el Instituto Federal Electoral- es hoy la mayor garantía y expresión del mencionado cambio. No sería exagerado decir que las reformas electorales constituyen el motor de la transición democrática. Por tal motivo, es forzoso referirse a ella en clave electoral. Pero no deja de lla-

33 Esa es la idea que sostiene Joseph L. Klesner: "Los regímenes que mantienen instituciones representativas y utilizan las elecciones como medios formales mediante los cuales el poder es transferido (aunque la transferencia real del poder tenga lugar tras bambalinas) ofrecen diferentes caminos institucionales a través de los cuales la democratización puede tener lugar. Caminos que pueden proveer la oportunidad a la oposición de perseguir la democratización sin recuurrir a la violencia y sin la ruptura del régimen". Klesner, Joseph L.: "An electoral route to democracy? Mexico's transition in comparative perspective", Comparative Politics, vol. 30, núm. 4, july 1998, pág. 479 
mar la atención la extraña paradoja que enfrentamos en el análisis: un país con amplia tradición en leyes incumplidas, sortea el cambio democrático construyendo un andamiaje legal-electoral detallado y completo. La instauración de las reglas de acceso al poder es parte de cualquier proceso democrático. Resta su aceptación generalizada que atañe a cambios culturales- y asunción como normas de conducta pública.

Si se ponderan estas dos características distintivas del sistema de poder mexicano, es bastante útil la perspectiva teórica de las transiciones para ubicar la nuestra.

La explicación difusa o de la "transición" como un nicho. El defecto en el análisis mexicano de la transición se expresa en dos vías. En una de ellas, la transición se convierte en el resguardo perfecto para criticar todo lo que somos y desear lo que nos falta; en la otra, la transición se configura en un estandarte, utilizable en el momento justo y para el tema preferido: un dirigente de transición, una mesa de transición o un presidente de transición.

El estado de la cuestión en el debate transitológico es, dado el defecto analítico, insatisfactorio y preocupante. En los once años que abarca esta investigación las similitudes interpretativas son raras y abundan las diferencias. Si bien es cierto que la polémica es el condimento principal de cualquier ciencia, máxime si se trata de la Ciencia Política, cuando no se visualizan pautas mínimas de coincidencia —el año de inicio de la transición es un ejemplo simple si se quiere, pero bastante claro de ello- la confrontación se convierte en dinámica permanente y desaparece el diálogo fructífero entre posturas divergentes.

Esta diversidad de posturas en torno al proceso de cambio mexicano nos indica que la transición se ha convertido en una especie de nicho. Es decir, un espacio cálido y seguro desde el cual todo se puede guardar, comentar, objetar, desmenuzar. En este tenor, la barrera que define los análisis rigurosos de los comentarios de coyuntura se pierde y sobrevive la confusión interpretativa.

Como discurso articulado desde este lugar salvaguardado, la "transición" parece renovarse de acuerdo a las circunstancias. La última renovación se observa con la presidencia en manos del PAN, pues se insiste con vehemencia en que la alternancia en el poder presidencial apenas es el primer paso de la transición, la cual reclama — al modo español— la convo- 
catoria a una negociación multilateral. El requisito rigorista de la alternancia deja el paso libre a la articulación de un gran pacto que, ahora sí, dé por terminado nuestro largo ciclo político de cambios. Así, el argumento se extiende en la obtención de la democracia: primero, la necesidad de tener elecciones limpias; luego, la alternancia en el poder presidencial; ahora, la necesidad de un "gran pacto democrático".

Aunque el regateo democrático persista y, junto con ello, el debate transitológico, resulta indispensable abrir los sentidos a otros problemas y otras vetas de investigación. Si, como hemos dicho antes, la circunstancia política ha cambiado, estamos obligados a extender los horizontes de interpretación. Habrá que dejar el nicho y arriesgarse a construir nuevas fuentes de explicación para el futuro democrático que nos aguarda.

Estas tres limitaciones expuestas se complementan unas con otras. Es decir, si el autoritarismo mexicano es anómalo en su constitución y expresión formal, al no marcar una frontera nítida respecto de la democracia, es comprensible la dificultad explicativa para encontrar los momentos cumbres de la transición. No podemos extrañarnos, en consecuencia, de que la transición mexicana haya tenido el mismo carácter anómalo - extraña e irregular en su duración y modalidad-y, por tanto, su carrera histórica no pueda ser aprehendida con facilidad. En otros términos, la multiplicidad de visiones y perspectivas sostenidas por los autores mexicanos son solo un reflejo del anómalo proceso de cambio vivido en el país.

Comparativamente, otras experiencias históricas resumen un proceso de esta naturaleza en una media temporal de dos años. ${ }^{34}$ El proceso mexicano sale de la regla. Desde nuestro punto de vista, se trata de un movimiento largo, continuo y oscilatorio, con un antecedente clave en el movimiento estudiantil de 1968, pero que comienza en 1977, atraviesa una serie de rupturas y reformas — de distinta calidad y dimensión- y concluye, instalados en la manía electoral, en los comicios de 1997. Es, en ese tenor, un proceso que abarca 20 años.

¿Por qué este hecho marca el término del proceso de transición, si no hubo un suceso dramático que nos lo anunciara, como lo fue el triunfo del PAN en la presidencia? Porque en esos comicios por vez primera las condiciones institucionales para la derrota del PRI estaban dadas, y éste parti-

34 Esa es la media de las transiciones democráticas vividas en Europa del Este, según Alcántara Sáez, Manuel: "Una comparación entre modelos de transición hacia la democracia: Los casos de España, América Latina y Europa Oriental”, en Alcántara Sáez, Manuel et al.: Procesos de transición a la democracia: Estudios comparativos, San José, 1992, págs. 13-57. 
do perdió la mayoría absoluta en la Cámara de Diputados. A la conciencia de la derrota, que es vital en el establecimiento de una democracia, le sigue la conciencia de la aceptación, no dudar de los resultados ni de las reglas de competencia previamente establecidas. El consenso en torno a dichos elementos puede ofrecerse de dicho - que así lo expresen los actores políticos- y de facto — que así lo practiquen los actores políticos.

En síntesis, en términos electorales no hay nada que objetar. Por eso la transición ha terminado, incluso desde antes de que la alternancia fuese un hecho. Nuestra transición ha sido extensa, pacífica y pausada, embarcada en dos polos dispares: la continuidad y el cambio. Las reformas electorales se tensaban por estas dos lógicas opuestas, la de la conservación, al procurarse mantener el predominio del PRI aún con instituciones de orientación democrática, y la ruptura, al minarse gradualmente su legitimidad con la aparición de otras alternativas partidarias.

Con esta idea de la transición en mente, debemos prevenirnos de dos vicios. Por un lado, de los traslados esquemáticos de experiencias distintas - la española es el ejemplo común, aunque no están exentas las latinoamericanas para justificar el carácter único de la transición mexicana ${ }^{35}$ pues está visto que México comparte con otros países la característica temporal que hemos destacado; y por el otro, de la fijación exacta e inflexible de un momento electoral cumbre que haga distinguible el paso del autoritarismo a la democracia, pues la democracia mexicana se construyó gradualmente mediante una serie de reformas institucionales de corto alcance.

En esa dirección, podemos afirmar que el salto democrático está dado. Resta solamente que adecuemos nuestras impresiones a la nueva realidad que se asoma a la vista, la cual se atisba promisoria.

\section{Apéndice: clasificando los textos electorales de la transición mexicana}

La clasificación de textos partió de dos elementos. Por un lado, la evaluación del "uso conceptual del marco teórico de las transiciones", teniendo como referente un esquema teórico (Cuadro 1) elaborado a partir de la

35 Al respecto, véase Camou, Antonio: "Transición democrática y gobernabilidad en México: una mirada desde el espejo latinoamericano", en Labastida Martín del Campo, Julio et al. (coords.): Transición democrática y gobernabilidad. México y América Latina, México, 2000, págs. 219-246. 
revisión detallada de cinco autores considerados "clásicos", en el tema: Morlino, ${ }^{36} \mathrm{O}^{\prime}$ Donnell y Schmitter, ${ }^{37}$ Przeworski ${ }^{38}$ y Rustow. ${ }^{39}$

El esquema presenta las siguientes características:

1. Excluye aquellos elementos que no son propios de la transición: en Morlino, el hundimiento, la consolidación democrática, la persistencia estable y la persistencia inestable; en O’Donnell y Schmitter, la socialización y el momento económico; en Rustow, la fase de habituación.

2. Incorpora una fase precedente a la transición, el régimen autoritario, y otra sucedánea, la instauración del régimen democrático. La transición misma la divide en dos procesos, simultáneos y/o secuenciales, autónomos y/o dependientes uno del otro: liberalización y democratización.

3. Resalta un componente, que está a medio camino entre la democratización y la instauración democrática: la negociación de las reglas político-electorales que dan pie a la realización de elecciones libres, limpias y competitivas.

El segundo elemento se refiere a los criterios asumidos en la selección de textos. Se eligieron los escritos mexicanos que:

1. Abordaran, de modo general o particular: a) los partidos políticos (como sistema o por separado), b) las elecciones (en sus distintos niveles, federales, estatales o municipales), y/o c) la legislación electoral y sus reformas. La idea era que en el título y/o en el contenido apareciera alguno de estos tres aspectos definitorios.

2. Cubrieran un periodo de once años, de 1988 a 1998, en vista de que: a) a fines de los años ochenta, la euforia por las transiciones se hizo patente en la publicación de libros y artículos, lo cual repercutió en la

36 Morlino, Leonardo: Cómo cambian los regímenes políticos, Madrid, 1985, 307 págs.; y Morlino, Leonardo: "Los autoritarismos" y "Las democracias", en Pasquino, Gianfranco (comp.): Manual de ciencia política, Madrid, 1996, págs. 79-177.

37 O’Donnell, Guillermo, y Schmitter, Philippe C.: Transiciones desde un...

38 Przeworski, Adam: "Algunos problemas en el estudio de la transición hacia la democracia”, en O’Donnell, Guillermo et al., Transiciones desde un gobierno autoritario. Vol. 3., 1994, págs. 79-104; y Przeworski, Adam: Democracia y mercado. Reformas políticas y económicas en la Europa del Este y América Latina, New York, 1995, 356 págs.

39 Rustow, Dankwart A.: "Transiciones a la democracia. Hacia un modelo dinámico", en Merino Huerta, Mauricio (coord.): Cambio político y gobernabilidad, México, 1992, págs. 151-178. 
política y en la academia mexicanas; y b) dos coyunturas electorales son definitorias en la transición mexicana, las de 1988 y 1997, las cuales era necesario reflejar en esta clasificación.

3. Tuvieran respaldo institucional, es decir, que estuvieran amparados — preferentemente- por alguna institución académica ${ }^{40}$ a fin de rescatar solo los que tuvieran rigor analítico. ${ }^{41}$

40 Se recurrió a la revisión de catálogos de las siguientes instituciones educativas: Centro de Investigación y Docencia Económicas (CIDE), Centro de Investigaciones y Estudios Superiores en Antropología Social (CIESAS), El Colegio de México (ColMex), Facultad Latinoamericana de Ciencias Sociales (Flacso), Instituto de Investigaciones Dr. José María Luis Mora (Instituto Mora), Universidad Autónoma Metropolitana (UAM) y Universidad Nacional Autónoma de México (UNAM).

41 En suma, se seleccionaron 32 trabajos, de los cuales 26 tienen respaldo institucional y 6 carecen de él. Estos 6 son: Cordera Campos, Rolando et al.: "Transición a la democracia: más allá del 21 de agosto", en Pascual Moncayo, Pablo (coord.): Las elecciones de 1994, México, 1995, págs. 4161; Loaeza, Soledad: "La lenta construcción..."; Merino, Mauricio: "Democracia, después...”; Romero, Jorge Javier: "El pantano de la transición mexicana", Nexos, núm. 176, agosto, México, 1992, págs. $37-$ 45; Sánchez Susarrey, Jaime: "Estado y Perspectivas...”; y Woldenberg, José: "El claro - oscuro de la transición”, en Cambio XXI, Fundación Mexicana (coord.): Las transiciones a..., págs. 281-293. 


\section{Cuadros}

\section{CUADro 1 \\ MODELO PARA LA COMPARACIÓN \\ TRANSICIÓN DEL AUTORITARISMO A LA DEMOCRACIA}

Fases

Dimensiones

1. El régimen autoritario. Estructura del régimen autoritario:

a) Origen.

b) Composición.

c) Grado de movilización.

d) Grado de institucionalización.

e) Principios de legitimidad.

Causas de crisis o erosión:

a) Pérdida de legitimidad.

b) Desempeño económico (éxito o fracaso).

c) Transformaciones socioeconómicas.

d) Separación de la coalición dominante.

e) La muerte del fundador del régimen.

f) Movilización social.

g) Presión del exterior (derrota militar, ocupación de una potencia extranjera).

2. Transición.

Intervalo de tiempo que media entre la crisis del régimen autoritario y la instauración del régimen democrático.

Dos procesos:

a) Liberalización.

- Redefinición y ampliación de los derechos civiles en los planos individual y colectivo.

- Proceso controlado "desde arriba", que pretende ampliar la base social del régimen, teniendo como resultado la organización autónoma de la sociedad civil.

b) Democratización.

- Redefinición y ampliación de los derechos políticos.

- Pacto democrático: negociaciones para seleccionar las instituciones democráticas que procuren el acatamiento voluntario de los actores políticos.

- Convocatoria a elecciones: reglas políticas que determinan a) las alternativas políticas posibles (dirigentes, políticos y partidos que participan), b) los cargos en disputa, y c) la forma (fórmula) más apropiada para distribuirlos.

3. La instauración del régimen democrático.
Acuerdos democráticos como transacción institucional contingente.

Aceptación y funcionamiento de las nuevas normas y estructuras de autoridad, lo cual implica que ningún actor está en posibilidad de alterar a su conveniencia ni las instituciones instauradas, ni los resultados del proceso políitico formal.

Expresiones:

a) La renovación periódica de la elite gobernante.

b) La posibilidad de la alternancia.

c) La realización de elecciones libres y competitivas.

d) La aparición de partidos y el establecimiento (o restablecimiento) de un sistema de partidos competitivo. 
LOS ESTUDIOS ELECTORALES EN MÉXICO (1988-1998)

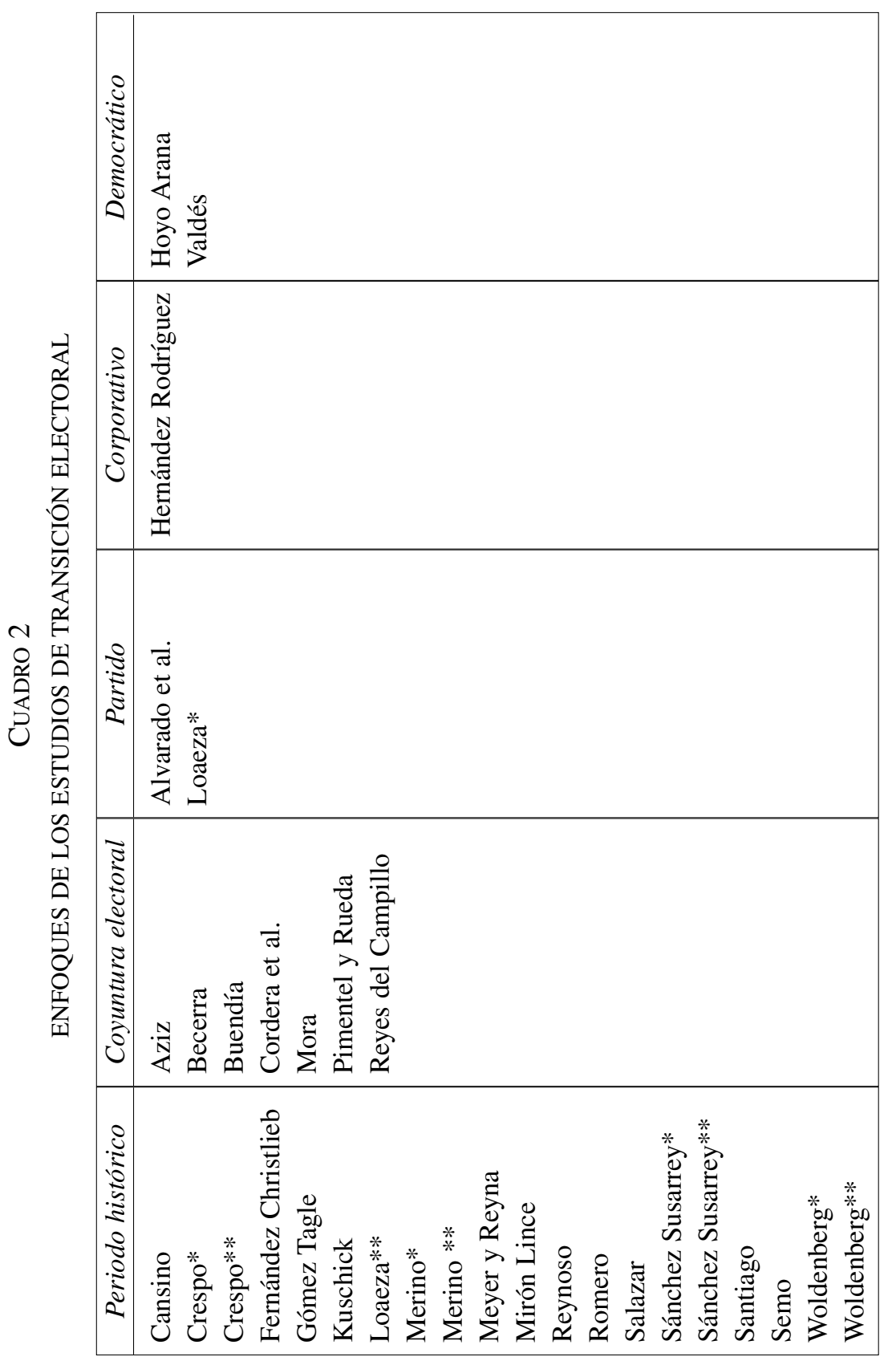

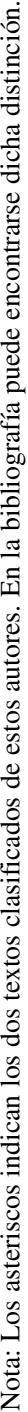


MIGUEL ARMANDO LÓPEZ LEYVA

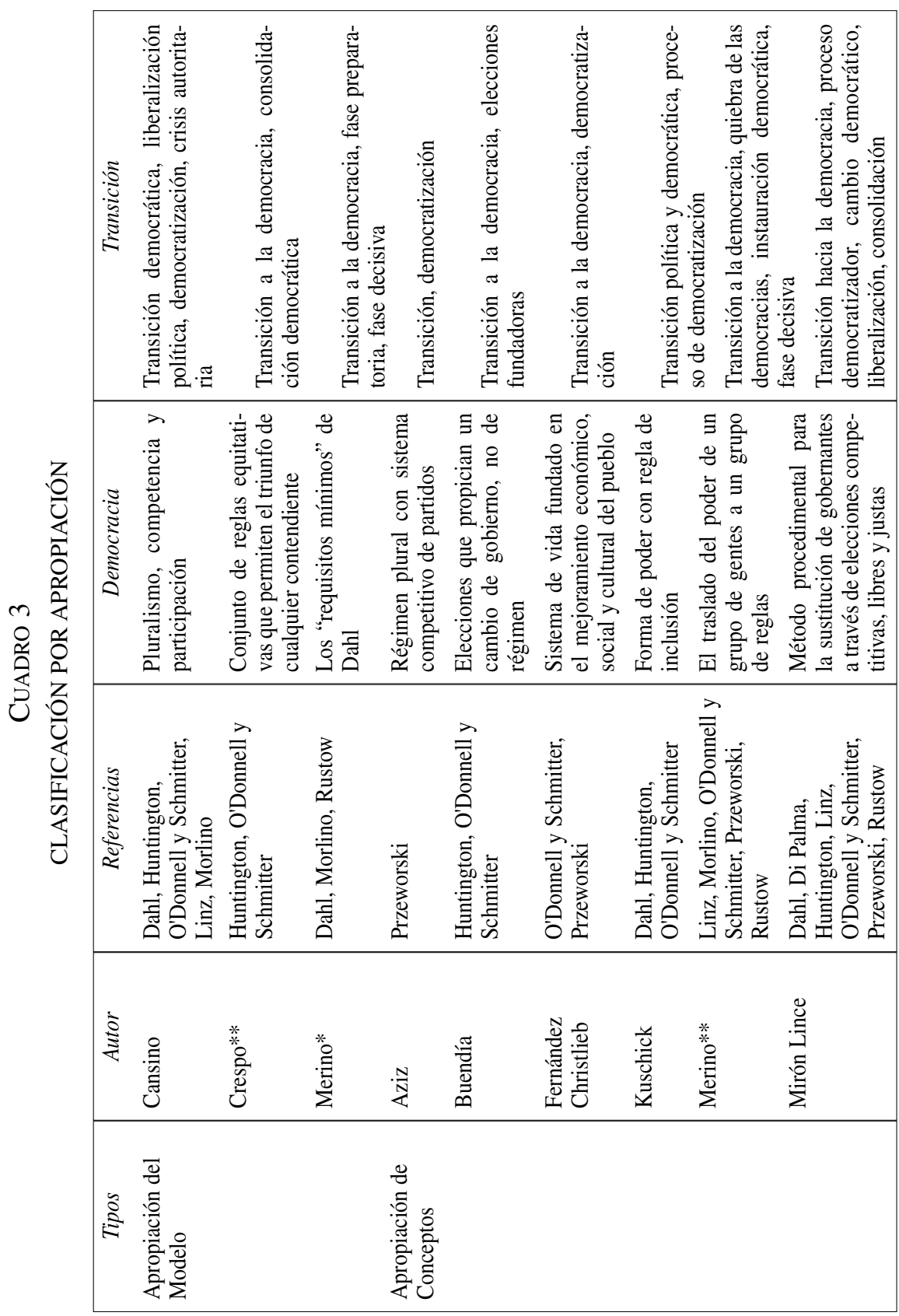


LOS ESTUDIOS ELECTORALES EN MÉXICO (1988-1998)

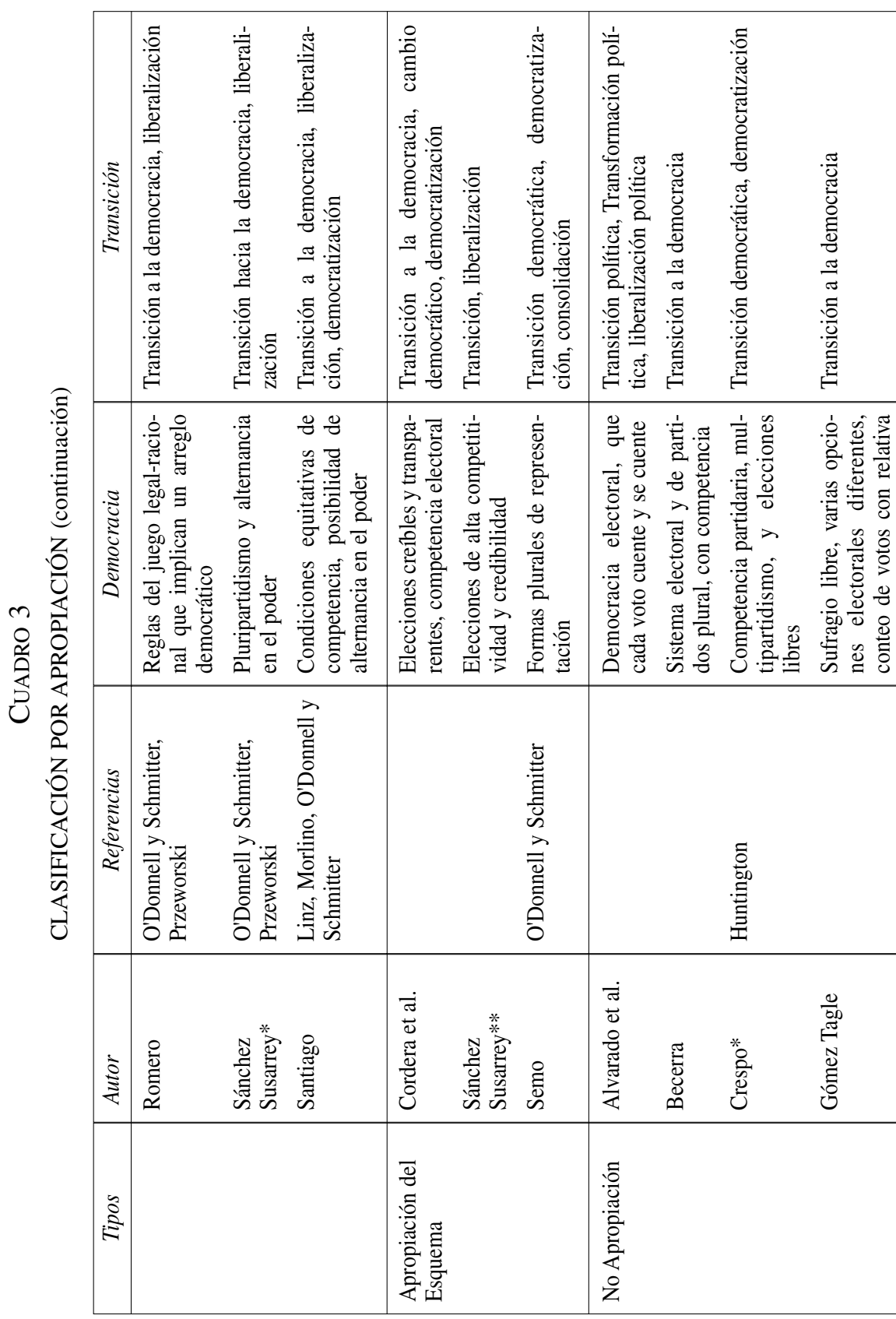


MIGUEL ARMANDO LÓPEZ LEYVA

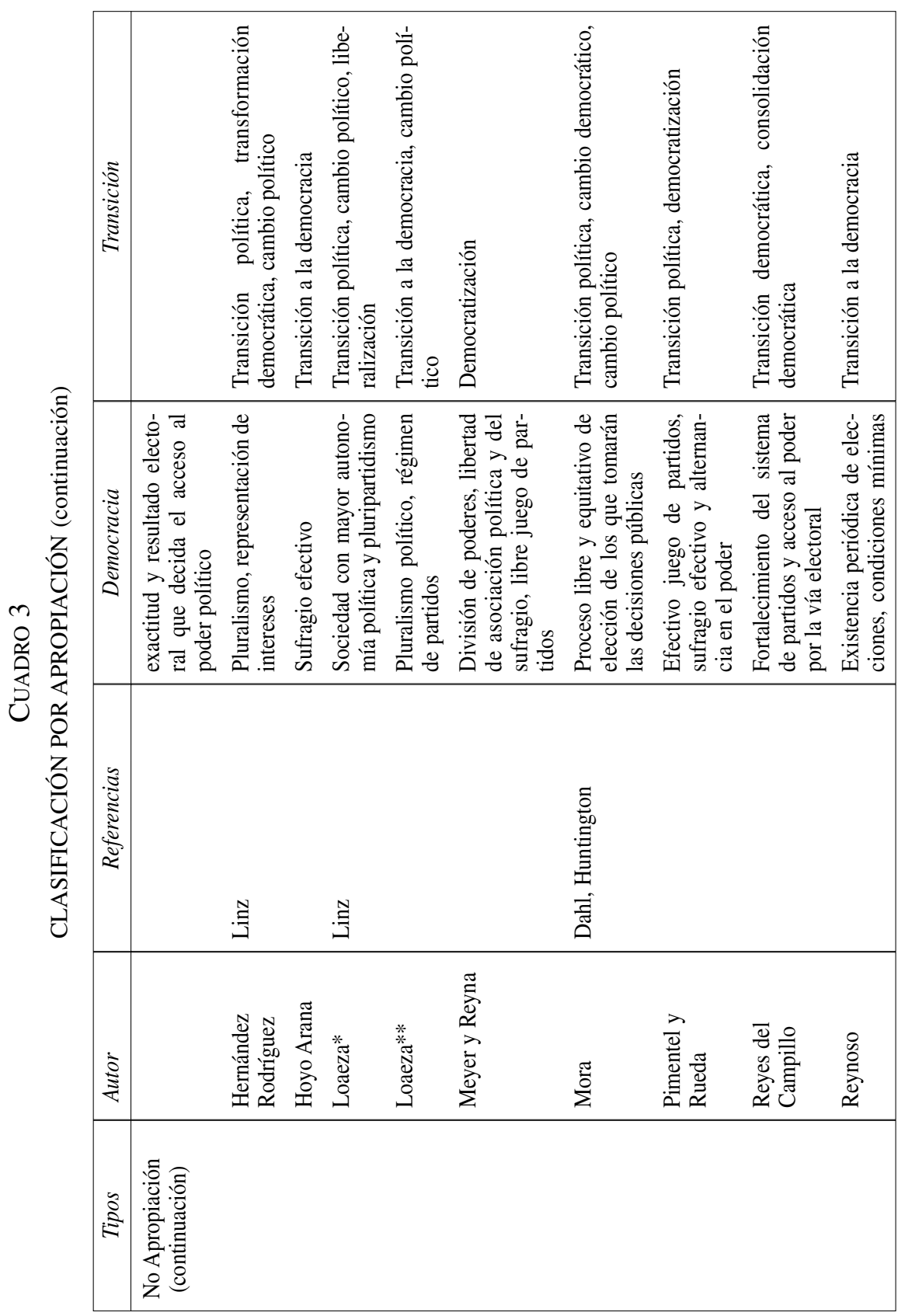


LOS ESTUDIOS ELECTORALES EN MÉXICO (1988-1998)

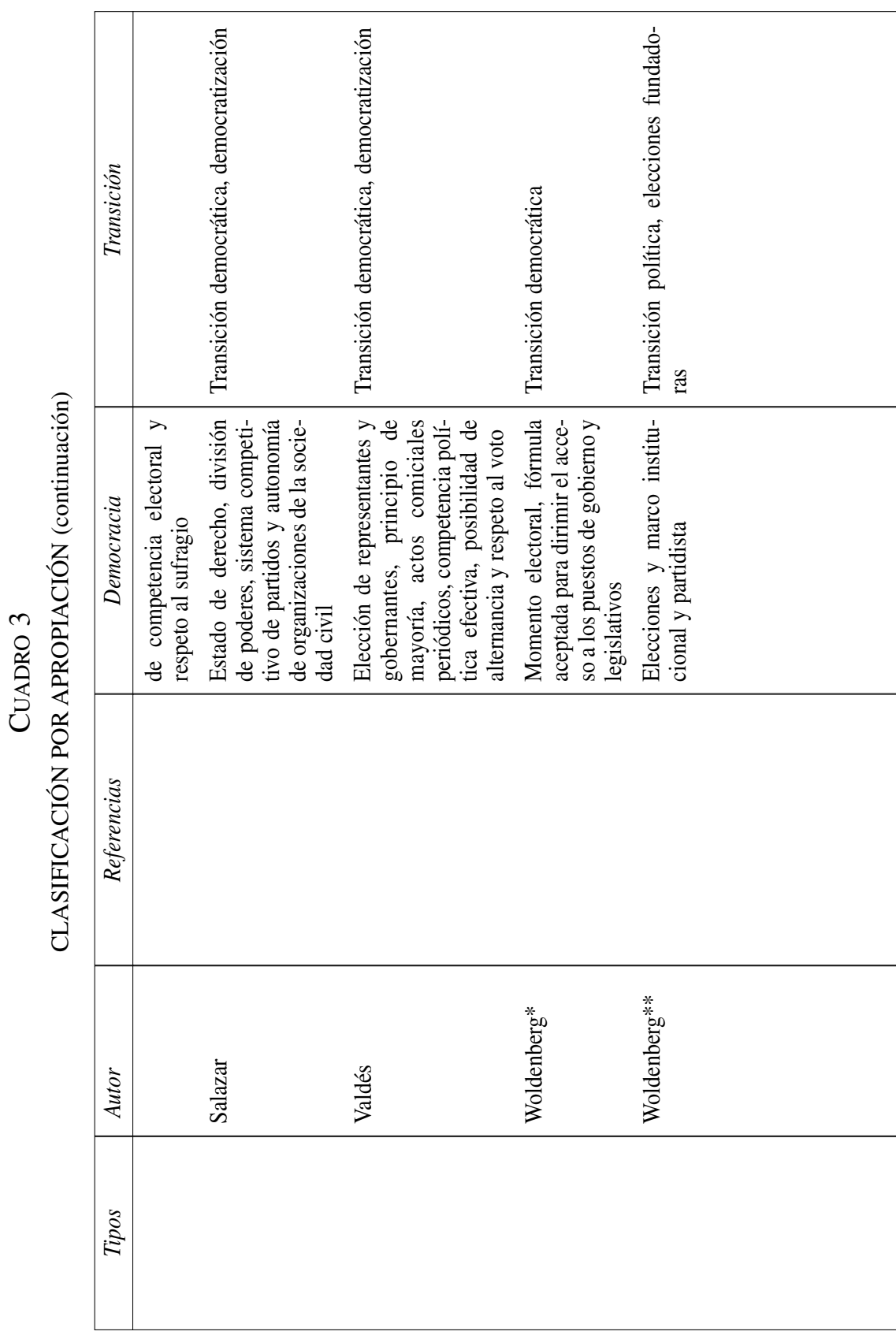


MIGUEL ARMANDO LÓPEZ LEYVA

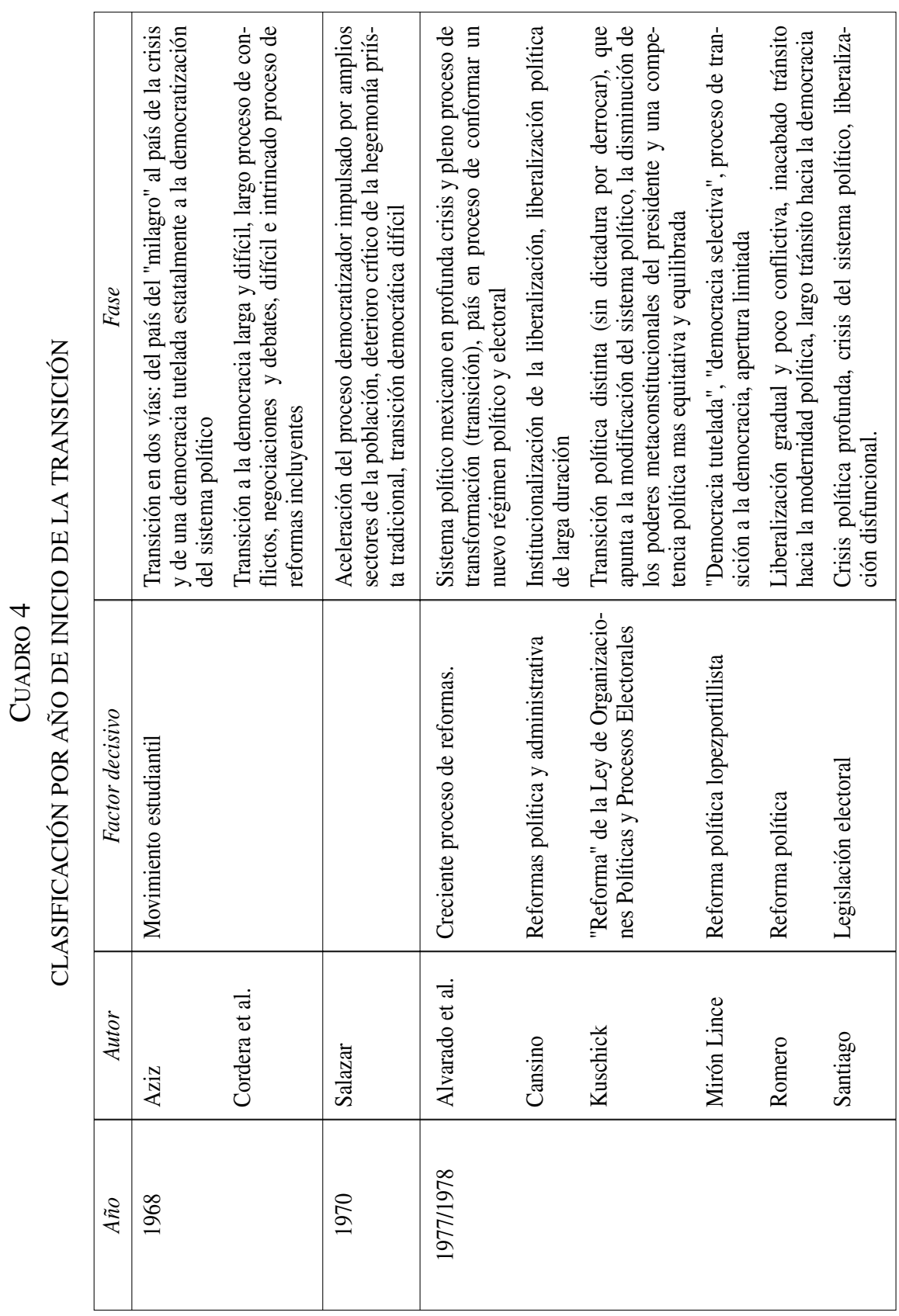




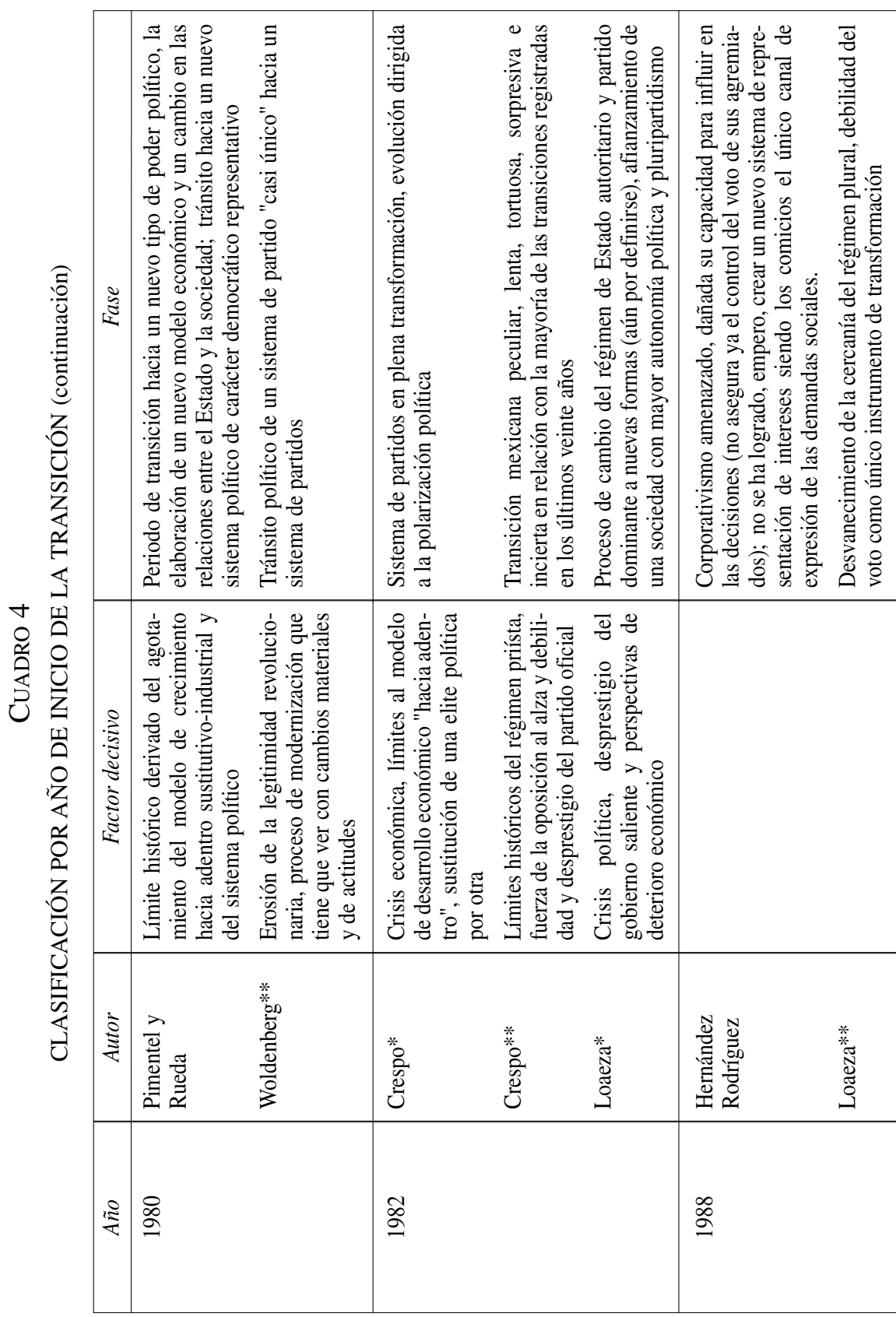


MIGUEL ARMANDO LÓPEZ LEYVA

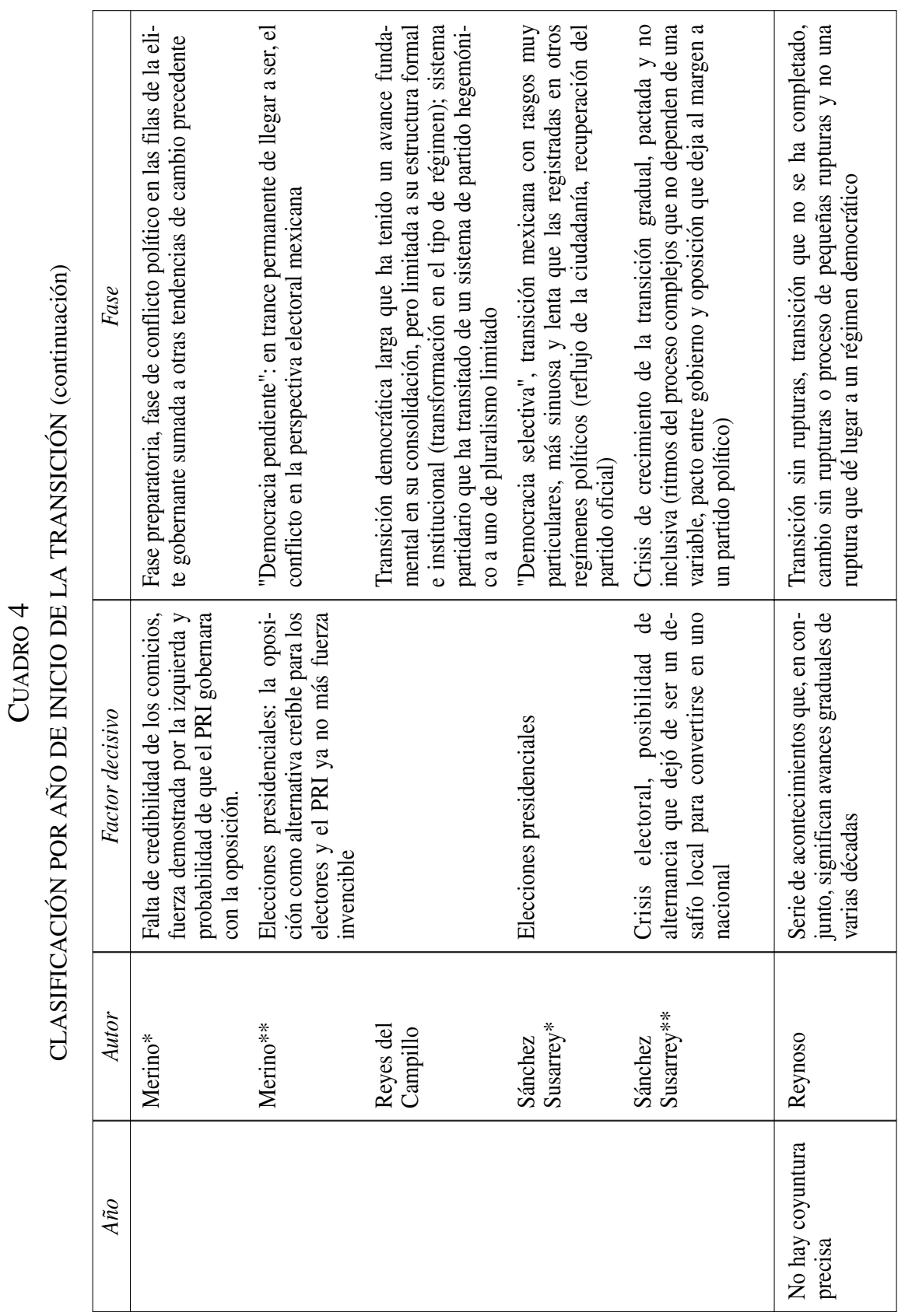


LOS ESTUDIOS ELECTORALES EN MÉXICO (1988-1998)

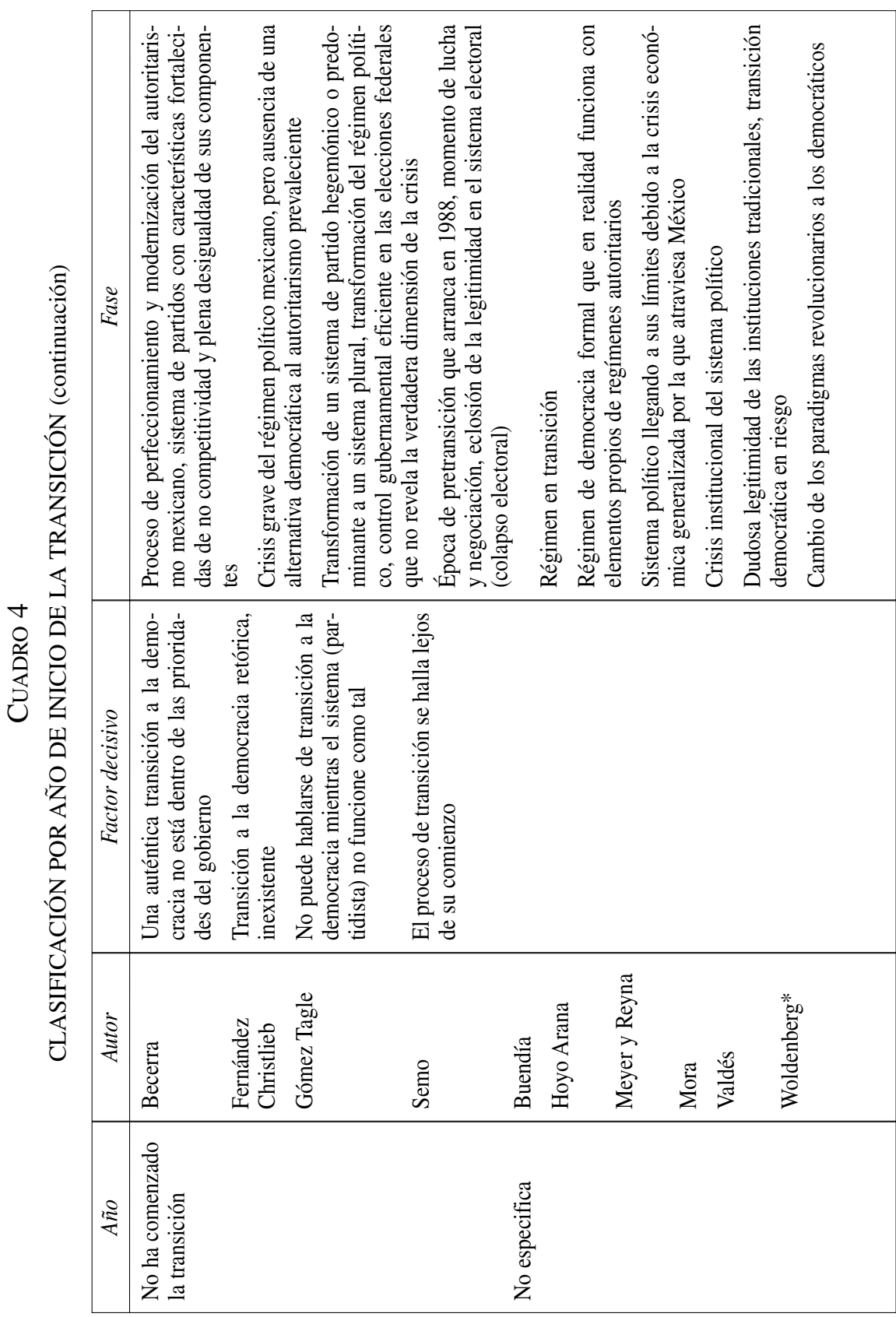




\section{Bibliografía}

\section{Textos Teóricos}

Alcántara Sáez, Manuel: "Una comparación entre modelos de transición hacia la democracia: los casos de España, América Latina y Europa Oriental", en Alcántara Sáez, Manuel et al.: Procesos de transición a la democracia: estudios comparativos, San José, Centro de Asesoría y Promoción Electoral del Instituto Interamericano de Derechos Humanos, 1992, págs. 13-57.

Collier, Ruth Berins: "Democratic transition", en Barry Clarke, Paul, y Foweraker, Joe (ed.): Encyclopedia of Democratic Thought, London, Routledge, 2001, págs. 213-217.

Dahl, Robert: Un prefacio a la teoría democrática, México, Gernika, 1987.

Hermet, Guy: "Las elecciones en los regímenes autoritarios: bosquejo de un marco de análisis”, en Hermet, Guy et al., ¿Para qué sirven las elecciones?, México, Fondo de Cultura Económica, 1982, págs. 18-53.

Linz, Juan: "Una teoría del régimen autoritario: el caso de España”, en Allardt, Erik, y Rokkan, Stein (eds.): Mass politics: studies in political sociology, New York, The Free Press, 1970, págs. 203-263.

Linz, Juan: "Totalitarian and authoritarian regimes", en Greenstein, F. I., y W. Polsby, Nelson (ed.): Handbook of political science. Vol. III. Macropolitical theory, Reading, Mass., Addeson Wesley, 1975, págs. 175-373.

Linz, Juan: El factor tiempo en un cambio de régimen, México, Instituto de Estudios para la Transición Democrática, 1994.

Morlino, Leonardo: Cómo cambian los regímenes políticos, Madrid, Centro de Estudios Constitucionales, 1985.

Morlino, Leonardo: "Los autoritarismos" y "Las democracias", en Pasquino, Gianfranco (comp.): Manual de ciencia política, Madrid, Alianza Universidad, 1996, págs. 79-177.

Nohlen, Dieter: Sistemas electorales y partidos políticos, México, Fondo de Cultura Económica/Universidad Nacional Autónoma de México, 1995.

O’Donnell, Guillermo, y C. Schmitter, Philippe: Transiciones desde un gobierno autoritario. Vol. 4. Conclusiones tentativas sobre las democracias inciertas, Buenos Aires, Paidós, 1994.

Przeworski, Adam: "Algunos problemas en el estudio de la transición hacia la democracia", en O'Donnell, Guillermo et al.: Transiciones desde un gobierno autoritario. Vol.3. Perspectivas comparadas, Barcelona, Paidós, 1994, págs. 79-104. 
Przeworski, Adam: Democracia y mercado. reformas políticas y económicas en la Europa del Este y América Latina., New York, Cambridge University Press, 1995.

Rustow, Dankwart A.: "Transiciones a la democracia: hacia un modelo dinámico", en Merino Huerta, Mauricio (coord.): Cambio político y gobernabilidad, México, Colegio Nacional de Ciencias Políticas y Administración Pública, Consejo Nacional de Ciencia y Tecnología, 1992, págs. 151-178.

\section{Textos Mexicanos}

Alvarado Mendoza, Arturo et al.: "Partido Revolucionario Institucional: contexto, situación política y escenarios electorales", Mexican Studies/ Estudios Mexicanos, vol. 13, núm. 2, summer 1997, págs. 325-362.

Aziz Nassif, Alberto: "El 6 de julio y el país de la transición", Incertidumbre y democracia en México, Cuadernos de la Casa Chata, núm. 177, Centro de Investigaciones y Estudios Superiores en Antropología Social, México, 1990, págs. 37-72.

Becerra, Pablo Javier: "Las elecciones de 1991: la transición difícil”, Polis 91 (Anuario de Sociología), México, Universidad Autónoma Metropolitana Iztapalapa, 1991, págs. 197-213.

Buendía Laredo, Jorge: "Incertidumbre y comportamiento electoral en la transición democrática: la elección mexicana de 1988", Política y Gobierno, vol. IV, núm. 2, segundo semestre de 1997, págs. 347-375.

Cansino, César: "La transición política" y "Cambio y continuidad del sistema de partidos", en Construir la democracia. Límites y perspectivas de la transición en México, México, Miguel Angel Porrúa/Centro de Investigación y Docencia Económicas, 1995, págs. 13-49 y 81-97.

Cordera Campos, Rolando et al.: "Transición a la democracia: más allá del 21 de agosto", en Pascual Moncayo, Pablo (coord.): Las elecciones de 1994, México, Cal y Arena/Instituto de Estudios para la Transición Democrática, 1995, págs. 41-61.

Crespo, José Antonio: "La evolución del sistema de partidos en México", Foro Internacional, 124, vol. XXXI, núm. 4, abril-junio 1991, págs. 599-622. (*)

Crespo, José Antonio: Institucionalización autoritaria y consolidación democrática: el caso de México (Documentos de Trabajo, núm. 47), Centro de Investigación y Docencia Económicas, México, 1997. (**)

Fernández Christlieb, Paulina: "Partidos políticos y sociedad civil ante la inexistente transición a la democracia en el México de hoy", en Rodríguez Araujo, Octavio (coord.): Transición a la democracia. Diferentes perspectivas, México, La Jornada, Centro de Investigaciones Interdisciplinarias en Ciencias y Humanidades - UNAM, 1996, págs. 193-212. 
Gómez Tagle, Silvia: La transición inconclusa: treinta años de elecciones en México, México, Centro de Estudios Sociológicos de El Colegio de México, 1997.

Hernández Rodríguez, Rogelio: "La difícil transición política en México", Mexican Studies/Estudios Mexicanos, vol. 8, núm. 2, summer 1992, págs. 237-257.

Hoyo Arana, José Luis: "Las elecciones de 1991 y las posibilidades de la transición a la democracia”, Estudios Políticos, tercera época, núm. 10, abril-junio, 1992, págs. 73-85.

Kuschick, Murillo: "Transición, partidos políticos y procesos electorales en Brasil y México", Sociológica, núm. 30, enero-abril de 1996, págs. 89-108.

Loaeza, Soledad: "Derecha y democracia en el cambio político mexicano: 19821988”, Foro Internacional, 120, vol. XXX, núm. 4, abril-junio, 1990, págs. 631-658. (*)

Loaeza, Soledad: "La lenta construcción del pluralismo mexicano", en Couffignal, Georges (comp.): Democracias posibles. El desafio latinoamericano, Buenos Aires, Fondo de Cultura Económica, 1994, págs. 167-181. (**)

Merino, Mauricio: "Democracia, después", en La democracia pendiente: ensayos sobre la deuda política de México, México, Fondo de Cultura Económica, 1993, págs. 65-95. (*)

Merino, Mauricio: “¿El conflicto como condición de la democracia? Límites y expectativas de la transición democrática en México", Política y Gobierno, vol. I, núm. 1, enero-junio 1994, págs. 127-138. (**)

Meyer, Lorenzo, y Reyna, José Luis: "México. el sistema y sus partidos: entre el autoritarismo y la democracia", en Meyer, Lorenzo, y Reyna, José Luis (coords.): Los sistemas políticos en América Latina, México, Siglo XXI/Universidad de las Naciones Unidas, 1989, págs. 305-328.

Mirón Lince, Rosa María: "Elecciones y transición democrática en México", Estudios Políticos, tercera época, núm. 12, octubre-diciembre, México, 1992, págs. 7-22.

Mora Heredia, Juan: "Electores y democracia en el México de la transición", El Cotidiano, núm. 65, noviembre, México, 1994, págs. 82-83 y 94-97.

Pimentel G., Nuri y J. Francisco Rueda: "México, julio de 1988: ¿hacia una transición democrática?", Iztapalapa, año 8, núm. 16, julio-diciembre, México, 1988, págs. 19-32.

Reyes del Campillo L., Juan: "La transición se consolida", El Cotidiano, núm. 85, septiembre-octubre, México, 1997, págs. 4-12.

Reynoso, Víctor Manuel: "Las razones y las formas de una transición gradual. México 1988-1994”, en Dutrénit Bielous, Silvia (coord.): Huellas de las transiciones políticas. Partidos y elecciones en América Latina, México, Instituto Mora, 1998, págs. 162-208.

Romero, Jorge Javier: "El pantano de la transición mexicana”, Nexos, núm. 176, agosto, México, 1992, págs. 37-45. 
Salazar, Luis: "Partidos políticos y transición a la democracia en México", Sociológica, año 4, núm. 11, septiembre-diciembre, México, 1989, págs. 27-42.

Sánchez Susarrey, Jaime: "México: la transición democrática aquí y ahora", en Barros Horcasitas, José Luis et al. (comps.): Transición a la democracia y reforma del estado en México, México, Universidad de Guadalajara/Miguel Angel Porrúa/Facultad Latinoamericana de Ciencias Sociales, 1991, págs. 153-164. (*)

Sánchez Susarrey, Jaime: "Estado y perspectivas de la transición en México", en Cambio XXI, Fundación Mexicana (coord.): Las transiciones a la democracia, México, Miguel Angel Porrúa, 1993, págs. 311-327. (**)

Santiago Castillo, Javier: "Proceso de liberalización política y legislación electoral”, Polis 95 (Anuario de Sociología), Universidad Autónoma MetropolitanaIztapalapa, México, 1996, págs. 113-129.

Semo, Ilán: "Democracia de elites versus democracia societal: los paradigmas de la pretransición mexicana”, en Semo, Ilán et al, La transición interrumpida.

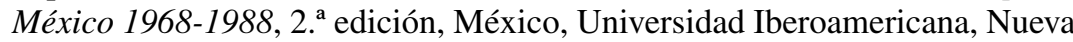
Imagen, 1994, págs. 191-228.

Valdés, Leonardo: "Elecciones y democracia en México: un ensayo", Iztapalapa, año 11, núm. 23, julio-diciembre, México, 1991, págs. 13-24.

Woldenberg, José: "El claro - oscuro de la transición”, en Cambio XXI, Fundación Mexicana (coord.): Las transiciones a la democracia, México, Miguel Angel Porrúa, 1993, págs. 281-293. (*)

Woldenberg, José: "Los partidos políticos en un momento de transición política: el caso de México", en Dutrénit, Silvia y Leonardo Valdés (coord.): El fin de siglo y los partidos políticos en América Latina, México, Instituto Mora/ Universidad Autónoma Metropolitana - Iztapalapa, 1994, págs. 51-70. (**)

\section{Textos complementarios}

Camou, Antonio: "Transición democrática y gobernabilidad en México: una mirada desde el espejo latinoamericano", en Labastida Martín del Campo, Julio et al. (coord.): Transición democrática y gobernabilidad. México y América Latina, México, Instituto de Investigaciones Sociales, Facultad Latinoamericana de Ciencias Sociales - Sede México, Plaza y Valdés, 2000, págs. 219-246.

Eisenstadt, Todd A.: “¿Remolinos en la tercera ola? Las transiciones prolongadas en las teorías sobre democratización", en Ortega Ruiz, Reynaldo Yunuen (ed.): Caminos a la democracia, México, El Colegio de México, 2001, págs. 87-120. 
Klesner, Joseph L.: “An electoral route to democracy? Mexico's transition in comparative perspective”, Comparative Politics, vol. 30, núm. 4, july, 1998, págs. 477-497.

Loaeza, Soledad: Incertidumbre y riesgo en transiciones prolongadas. La experiencia mexicana y el Partido Acción Nacional, México, Facultad Latinoamericana de Ciencias Sociales- Sede México, 2000, 31 págs. (Documentos de Trabajo, núm. 14).

Moreno, Alejandro: "La sociedad mexicana y el cambio", Este País, núm. 133, abril, 2002, págs. 78-82.

Ortega Ortiz, Reynaldo Yunuen: "Tipos de transición: un estudio comparativo de España y México", en Ortega Ruiz, Reynaldo Yunuen (ed.): Caminos a la democracia, México, El Colegio de México, 2001, págs. 267-321.

Schatz, Sara: Elite, Masses, and the Struggle for Democracy in Mexico. A culturalist approach, Westport: Praeger Publishers, 2000, 132 págs.

Schedler, Andreas: "The two - level game of democratization by elections", texto preparado para el Congress of the Canadian Association for Latin American and Caribbean Studies (CALACS), Antigua, Guatemala, 22-24 february 2001, 35 págs. 